\title{
The effects of the glycaemic control on the severity of the delirium in the advanced phase of Alzheimer's disease
}

\section{[version 1; peer review: 2 approved]}

\author{
Antonio Martocchia (D1), Marta Scarienzi1', Pietro Prunas', Enrico Bentivegna1, \\ Mauro Cacciafesta2, Paolo Martelletti (iD), Giorgio Sesti(iD1 \\ ${ }^{1}$ Sapienza University of Rome, ROMA CAPITALE, RM, 00100, Italy \\ 2Department of Cardiovascular, Respiratory, Nephrological, Anesthesiological and Geriatric Sciences, Sapienza University of Rome, \\ Rome, Italy
}

\author{
V1 First published: $16 \operatorname{Dec} 2020,9: 1470$ \\ https://doi.org/10.12688/f1000research.26022.1 \\ Latest published: $28 \mathrm{Jul}$ 2021, 9:1470 \\ https://doi.org/10.12688/f1000research.26022.2
}

\section{Abstract}

Background: Behavioural and psychological symptoms of dementia (BPSD) and delirium are common in advanced phases of Alzheimer's disease (AD).

Methods: Thirty-eight moderate-severe AD patients were enrolled ( $n=16$ affected by type 2 diabetes). Each patient received a comprehensive geriatric assessment (CGA) (including evaluation of BPSD and frailty), and a complete metabolic evaluation (including the measurement of the glycated haemoglobin, $\mathrm{HbA} 1 \mathrm{c}$ ).

Results: Both the hyper- and hypo-glycaemic extremes of the glycaemic spectrum worsened BPSD, but delirium was more susceptible to hypoglycaemic events. The severity of delirium was significantly related to cognitive function $(r=-0.585, p<0.001)$ and frailty $(r=+0.440, p<0.05)$.

Conclusions: The measurement of $\mathrm{HbA} 1 \mathrm{c}$ was useful for evaluating the risk of delirium in relationship to glycaemic control and nutritional status.

\section{Keywords}

Marigliano-Cacciafesta-polypathology-scale, glycaemic control, Alzheimer's disease, delirium

\section{Open Peer Review}

Approval Status

1 2

version 2

(revision)

28 Jul 2021

version 1

16 Dec 2020

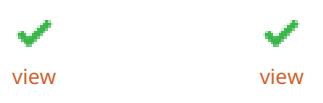

1. Sandra Sigala (D), University of Brescia, Brescia, Italy

2. Takahiko Nagamine iD, Director of Sunlight Brain Research Center, Hofu, Japan

Matsumoto Surgical Hospital, Hofu, Japan

Any reports and responses or comments on the article can be found at the end of the article. 
Corresponding author: Antonio Martocchia (antonio.martocchia@uniroma1.it)

Author roles: Martocchia A: Conceptualization, Formal Analysis, Methodology; Scarienzi M: Data Curation; Prunas P: Data Curation; Bentivegna E: Writing - Review \& Editing; Cacciafesta M: Resources; Martelletti P: Resources; Sesti G: Resources

Competing interests: No competing interests were disclosed.

Grant information: The author(s) declared that no grants were involved in supporting this work.

Copyright: (c) 2020 Martocchia A et al. This is an open access article distributed under the terms of the Creative Commons Attribution License, which permits unrestricted use, distribution, and reproduction in any medium, provided the original work is properly cited.

How to cite this article: Martocchia A, Scarienzi M, Prunas $P$ et al. The effects of the glycaemic control on the severity of the delirium in the advanced phase of Alzheimer's disease [version 1; peer review: 2 approved] F1000Research 2020, 9:1470

https://doi.org/10.12688/f1000research.26022.1

First published: 16 Dec 2020, 9:1470 https://doi.org/10.12688/f1000research.26022.1 


\section{Introduction}

Behavioural and psychological symptoms of dementia (BPSD) and delirium are common in the advanced phases of Alzheimer's disease (AD), whereas cognitive decline is prevalent in the first phases of the disease.

Both the hyper- and hypo-glycaemic extremes of the glycaemic spectrum may worsen cognitive functions in $\mathrm{AD}$ patients ${ }^{1-3}$, and nutrition plays an important role in the development of the delirium in frail older patients ${ }^{4}$.

The aim of this preliminary report was to evaluate the relationship between delirium and glycaemic control in the advanced phases of AD.

\section{Methods}

\section{Ethical statement}

The study involved human participants with metabolic syndrome in aging and it was performed in accordance with the ethical standards of the local institutional committee (S. Andrea Hospital, ID number 67910) and with the 1964 Helsinki declaration and its later amendments or comparable ethical standards. Written informed consent for participation and evaluation of data was obtained from the individual participants included in this study or from their caregivers, where ability to consent was affected by delirium.

\section{Participants}

We randomly (systematic sampling) enrolled 38 elderly patients ( $\mathrm{n}=11$ males and $\mathrm{n}=27$ females) from the outpatients of the S. Andrea Hospital of Rome, in 2019. From their medical records, the patients met the criteria for probable $\mathrm{AD}$ dementia proposed by the National Institute on Aging-Alzheimer's Association (NIA-AA) ${ }^{5}$ (Mini Mental State Examination (MMSE) score of 12.4+7.3, mean + standard deviation, in the moderate-severe stage of the disease). Prior to inclusion, subjects with other diseases, such as territorial infarction, intracranial haemorrhage, brain tumour, hydrocephalus, or severe white matter hyperintensities (WMH) were excluded from the study. Sixteen of the patients $(16 / 38,42 \%$ of the sample) were affected by type 2 diabetes (T2DM, according to 2020 American Diabetes Association, ADA, criteria $)^{6}$, undergoing treatment with oral glucose lowering agents $(n=13)$ or with insulin $(n=3)$.

\section{Assessments}

Each patient received from our group: a) a comprehensive geriatric assessment (CGA), including the evaluation of the Activity of Daily Living (ADL), the Instrumental Activities of Daily Living (IADL), the Cumulative Illness Rating Scale (CIRS) and the Marigliano-Cacciafesta Polypathology Scale $(\mathrm{MCPS})^{7,8}$; b) an anthropometric evaluation, including height, weight, body mass index (BMI), waist circumference, Mini Nutritional Assessment (MNA) ${ }^{9}$ c) a behavioural and psychological examination, using the Cornell's scale, the Clinical Dementia Rating scale (CDR), the Neuropsychiatric Inventory (NPI) and the Confusion Assessment Method (CAM, with CAM-severity $)^{10-12}$. An assessment of glucose metabolism, including fasting glycaemia and insulinaemia (excluded in insulin-treated patients), glycated haemoglobin (HbA1c) and insulin resistance by the means of the HOMA-index (glycemia $\mathrm{mg} / \mathrm{dl} \times$ insulinaemia $\mu \mathrm{U} / \mathrm{mol} / 405$ ) (excluded in insulin-treated patients) and an evaluation of renal function, measuring creatinine and glomerular filtration rate (GFR) estimated using the Chronic Kidney Disease Epidemiology Collaboration formula (CKD-EPI), was performed using a clinical chemistry analyzer (c16000 Architect System, Abbott Laboratories). A continuous glucose monitoring (FreeStyle Libre system) was used in selected patients with a high risk of hypoglycaemic events, or with great variability of glycaemia during the day.

\section{Statistical analysis}

For the statistical analysis, carried out using Primer of Biostatistics Version 7, one-way analysis of variance (ANOVA) was used for the evaluation of the differences between the groups of patients. The relationship between two variables was examined by the means of regression analysis. A $\mathrm{p}<0.05$ was assumed as significant. Data are presented as mean + standard deviation.

\section{Results}

The clinical characteristics of the $38 \mathrm{AD}$ patients with and without T2DM are described in Table $1^{13}$.

The MMSE scores were inversely and significantly related to CAM-S score $(r=-0.585, p<0.001)$, while MCPS scores were positively related to the CAM-S score $(r=0.440, p<0.05)$ (Figure 1a and 1b).

The regression analysis between $\mathrm{HbA1c}$ and MMSE score showed a concave downward " $\cap$ " parabola (not significant) with apex at $\mathrm{HbA} 1 \mathrm{c}$ of $10.5 \%$ and MMSE of 13.0. The regression analysis between $\mathrm{HbA1c}$ and the psychometric BPSD scales (Cornell, NPI and CAM-S) showed a "U" shape (concave upward parabola) (Cornell $\mathrm{p}<0.05, \mathrm{NPI}<0.01$ and CAM-S $\mathrm{p}<0.0001$ ) (Figure 2). The apices of the parabolas were at HbA1c of $6.9 \%$, $7.6 \%$ and $10.3 \%$, the levels that minimized the Cornell, NPI and CAM-S scores, respectively (Figure 2). Therefore, the mean $\mathrm{HbA1c}$ that minimized all the behavioural disorders was $8.3 \%$.

Continuous glucose monitoring in selected patients $(n=3)$ showed that, even if HbA1c level was within the normal range, either a great variability in glycaemia during the 24 hours or repeated hypo-glycaemic events during the night (up to 26 hypoglycaemic events in a single patient) were present (Figure 3).

\section{Discussion}

In our preliminary study, polypathology and frailty was associated with the severity of delirium as demonstrated by using the MCPS scale in correlation with the CAM-S scale.

To the best of our knowledge this is the first report about the association of the MCPS and CAM-S scale, whereas the MCPS was previously evaluated by our group in patients with comorbidities and frailty ${ }^{8}$. 


\begin{tabular}{|c|c|c|}
\hline & $\begin{array}{c}\text { AD patients } \\
\text { without } T 2 D M\end{array}$ & $\begin{array}{l}\text { AD patients } \\
\text { with T2DM }\end{array}$ \\
\hline Age (years) & $83.3+5.7$ & $82.3+4.2$ \\
\hline MMSE & $11.6+7.1$ & $12.7+7.5$ \\
\hline ADL (IADL $M$ and F) & 2.9+2.2 (M: 1.7+1.7; F: 1.2+1.8) & $2.7+1.8(\mathrm{M}: 1.4+1.5 ; \mathrm{F}: 0.7+1.0)$ \\
\hline MCPS & $48.6+10.5$ & $47.4+7.0$ \\
\hline CIRS-SI and -CI & $2.2+0.6$ and $4.8+2.2$ & $2.3+0.4$ and $5.6+1.4$ \\
\hline BMI & $24.4+7.0$ & $26.7+5.7$ \\
\hline Waist circumference $(\mathrm{cm})$ & M: $98.7+1.5 ; F: 90.3+22.6$ & M: $97.7+8.6 ; F: 89.1+15.2$ \\
\hline MNA & $17.4+6.0$ & $18.8+4.8$ \\
\hline Cornell & $14.2+8.6$ & $11.4+6.0$ \\
\hline CDR & $2.7+1.4$ & $2.2+1.1$ \\
\hline CAM & $2.7+1.5$ & $2.2+1.9$ \\
\hline CAM-S & $7.8+4.1$ & $4.7+3.7^{*}$ \\
\hline NPI & $53.7+28.5$ & $40.2+20.2$ \\
\hline Fasting glycaemia (mg/dl) & $94.5+11.2$ & $135.6+58.0$ \\
\hline Fasting insulinaemia ( $\mu \mathrm{u} / \mathrm{ml})$ & $6.0+2.6$ & $8.9+9.5$ \\
\hline $\mathrm{HbA1c}$ & $5.4+0.4 \%$ & $6.8+1.1 \%^{* * *}$ \\
\hline HOMA index & $1.4+0.6$ & $3.2+3.4^{*}$ \\
\hline GFR (CKD-EPI; ml/min) & $66.0+16.9$ & $64.9+23.4$ \\
\hline
\end{tabular}

MMSE, Mini Mental State Examination; ADL, Activity of Daily Living; IADL, Instrumental Activities of Daily Living; MCPS, Marigliano-Cacciafesta Polypathology Scale; CIRS, Cumulative Illness Rating Scale; SI, severity index; BMI, body mass index, MNA, Mini Nutritional Assessment; CDR, Clinical Dementia Rating scale; CAM, Confusion Assessment Method; CAM-S, CAM-severity; NPI, Neuropsychiatric Inventory; HbA1c, glycated haemoglobin; GFR, glomerular filtration rate; CKD-EPI, Chronic Kidney Disease Epidemiology Collaboration formula; M, male; F, female.

${ }^{*} p<0.05,{ }^{* *} p<0.01, * * * p<0.0001$.

$A_{\text {CAM-S }}$

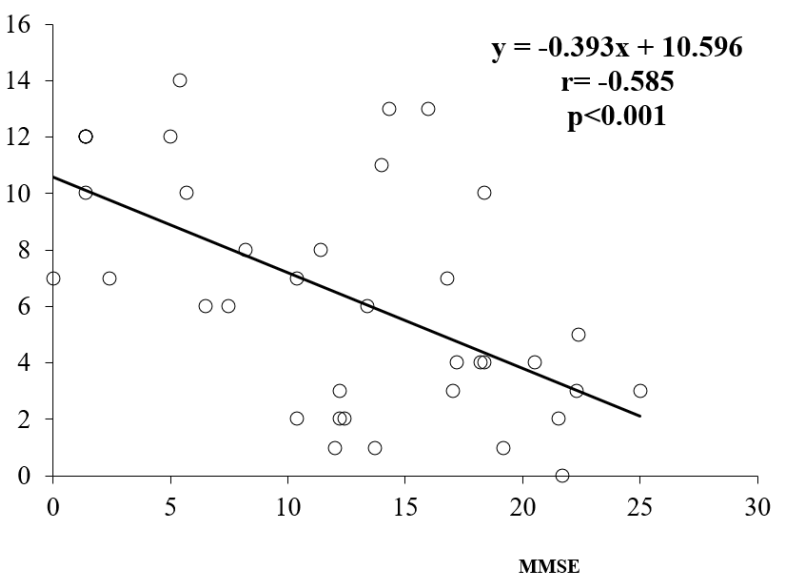

B CAM-S

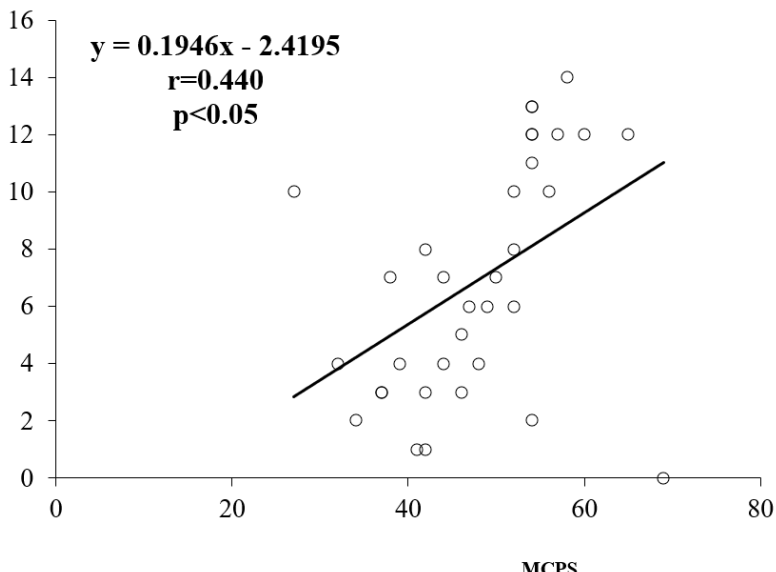

Figure 1. a) The relationship between MMSE and CAM-S scores. b) The relationship between MCPS and CAM-S scores. MMSE, Mini Mental State Examination; CAM-S, Confusion Assessment Method-severity; MCPS, Marigliano-Cacciafesta Polypathology Scale. 


\title{
NPI/Cornell/CAM-S
}

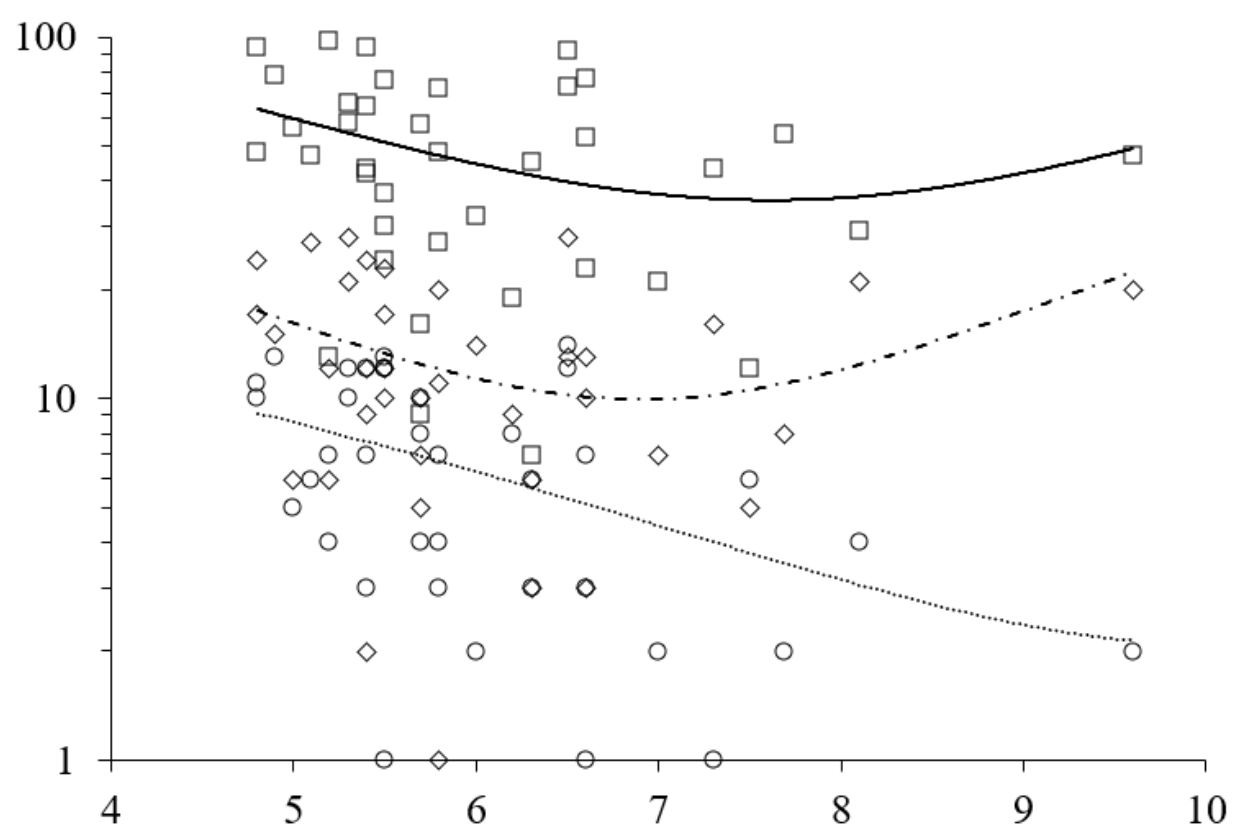

HbA1c

\author{
$\mathrm{NPI}=3.7 \mathrm{HbA1}^{2}-53.6 \mathrm{HbA1c}+239.5 ; \mathrm{R}^{2}=0.101, \mathrm{p}<0.01 . \square-\mathrm{NPI}$ \\ Cornell=1.7 HbA1c ${ }^{2}-23.6 \mathrm{HbA1c}+91.5 ; \mathrm{R}^{2}=0.122, \mathrm{p}<0.05 . \diamond-\cdot-$ Cornell \\ CAM-S $=0.3 \mathrm{HbA1}^{2}-5.1 \mathrm{HbA1c}+27.9 ; \mathrm{R}^{2}=0.175, \mathrm{p}<0.0001 . \circ \cdots \cdots \cdot \mathrm{CAM}-\mathrm{S}$
}

Figure 2. The relationship between the glycated haemoglobin (HbA1c) and the Neuropsychiatric Inventory (NPI), Cornell's scale and Confusion Assessment Method-severity (CAM-S) score.

Glycaemic control was associated with modification of BPSD and delirium in the advanced phases of $\mathrm{AD}$. In particular, delirium (as indicated by the CAM-S score) was more susceptible to the glycaemic control in its low range. As considered by point 7 (Metabolism and Nutritional state) of MCPS, high glucose levels increase the score of the MCPS scale $(+25)$ only in conditions of diabetes mellitus decompensation, with significant risks of development of delirium.

Glycaemic control modulated the appearance of BPSD and delirium with a polynomial U-shaped curve, with both the hyper- and hypo-glycaemic extremes of the glycaemic spectrum worsening BPSD. The regression equations showed that HbA1c levels between 6.9-10.3\% (mean 8.3\%) minimized BPSD, in agreement with International Diabetes Federation (2020) ${ }^{14}$ and ADA $(2020)^{6}$ guidelines for managing T2DM in older people. As matter of fact, in healthy older subjects (with few coexisting chronic illnesses, intact cognitive and functional status) a reasonable $\mathrm{HbA} 1 \mathrm{c}$ goal is $<7.5 \%$ (with fasting or preprandial glucose of $90-130 \mathrm{mg} / \mathrm{dl}$ ), whereas in complex/poor health patients (with more chronic illnesses, moderate-to severe cognitive impairment or $>2$ ADL dependencies) the reasonable HbAlc goal rises to $<8.5$ (with fasting or preprandial glucose of $100-180 \mathrm{mg} / \mathrm{dl}$ ) to avoid possible overtreatment, hypoglycaemic events and fall risk.

The HbA1c value of $6 \%$ corresponds to a mean glucose of $126 \mathrm{mg} / \mathrm{dl}$, with $95 \%$ prediction limits of $100-152 \mathrm{mg} / \mathrm{dl}$, which includes the lower goals for glycaemia (100-180 mg/dl) suggested by ADA standard of care ${ }^{15-17}$ in older frail patients with moderate-severe dementia. More than half of our patients $(22 / 38,58 \%)$ showed HbA1c levels lower than $6 \%$.

The reduction of one point $(\%)$ of $\mathrm{HbA1c}$ (from $6.8 \%$ to $5.8 \%$ ) was associated with an increase of +2.2 points in Cornell, +7.0 points in NPI and +0.2 in CAM-S scores. Because of the parabolic profiles of the curves, another reduction of one point of $\mathrm{HbA1c}$ (from $5.8 \%$ to $4.8 \%$ ) resulted in an exponential 

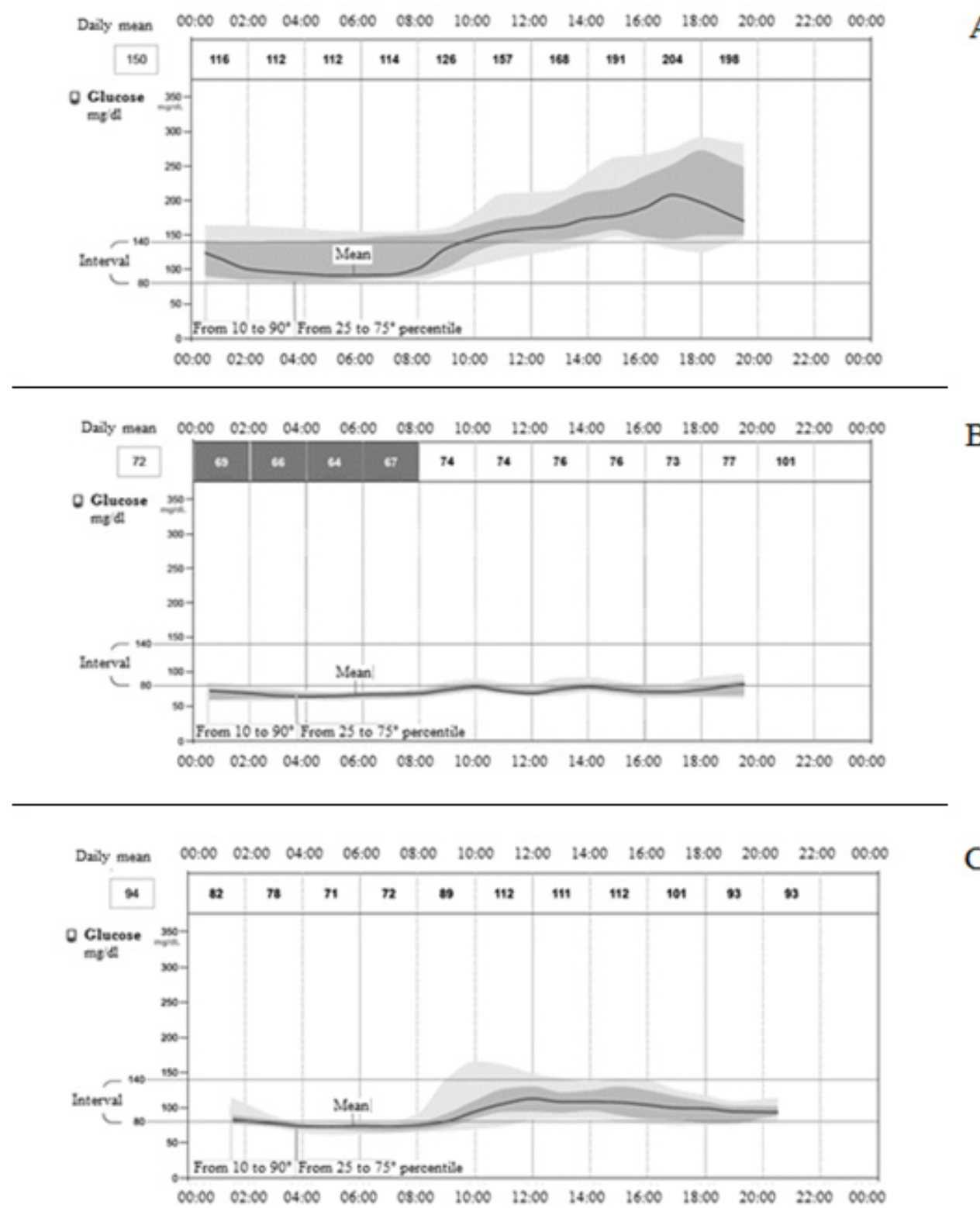

Figure 3. Continuous glucose monitoring in selected cases $(\mathbf{n}=\mathbf{3})$. A) Patient $A, 81$ years, MMSE=1.5, NPI=77, Cornell=13, CAM-S=17, HbA1c $=6.6 \%$, glucose mean $150 \mathrm{mg} / \mathrm{dl}$, above/in/under the interval 56/43/1\%, event of low glucose=0, mean duration=0. B) Patient B, 77 years, MMSE=13.7, NPI=30, Cornell=12, CAM-S=4, HbA1c=5.5\%, glucose mean $72 \mathrm{mg} / \mathrm{dl}$, above/in/under the interval 0/16/84\%, event of low glucose=26, mean duration=296 min. C) Patient C, 82 years, MMSE=10.5, NPI=52, Cornell=18, CAM-S=11, HbA1c=5.7\%, glucose mean $94 \mathrm{mg} / \mathrm{dl}$, above/in/under the interval 7/54/39\%, event of low glucose=4, mean duration=281 min.

increase of BPSD scores $(+5.6$ Cornell, +14.4 NPI and +2.6 CAM-S).

The variability of glycaemia seemed to be associated with greater BPSD in AD patients, although it was not possible to carry out a statistical analysis because of the few number of patients in the sample.
A

B

C
In conclusion, the measurement of $\mathrm{HbAlc}$ in elderly $\mathrm{AD}$ patients with advanced dementia (with and without T2DM) is recommended in order to evaluate glycaemic control (and nutritional status). The reduction of mean glycaemic levels (due to malnutrition in non-diabetic patients or overtreatment in diabetic patients) should be avoided by means of a multidimensional approach. 
Data availability

DANS EASY: The Glycaemic Control and the Severity of the Delirium. https://doi.org/10.17026/dans-Xq4-58fq ${ }^{13}$.
Data are available under the terms of the Creative Commons Zero "No rights reserved" data waiver (CC0 1.0 Public domain dedication).
1. Rizzo MR, Marfella R, Barbieri M, et al.: Relationships between daily acute glucose fluctuations and cognitive performance among aged type 2 diabetic patients. Diabetes Care. 2010; 33(10): 2169-2174. PubMed Abstract | Publisher Full Text | Free Full Text

2. Sakurai T, Kawashima S, Satake S, et al.: Differential subtypes of diabetic older adults diagnosed with Alzheimer's disease. Geriatr Gerontol Int. 2014; 14 Suppl 2: 62-70.

PubMed Abstract | Publisher Full Text

3. Yaffe K, Falvey C, Hamilton N, et al.: Diabetes, glucose control, and 9-year cognitive decline among older adults without dementia. Arch Neurol. 2012; 69(9): 1170-1175.

PubMed Abstract | Publisher Full Text | Free Full Text

4. Rosted E, Prokofieva T, Sanders S, et al:: Serious consequences of malnutrition and delirium in frail older patients. J Nutr Gerontol Geriatr. 2018; 37(2): 105-116.

PubMed Abstract | Publisher Full Text

5. McKhann GM, Knopman DS, Chertkow $\mathrm{H}$, et al: The diagnosis of dementia due to Alzheimer's disease: recommendations from the National Institute on Aging-Alzheimer's Association workgroups on diagnostic guidelines for Alzheimer's disease. Alzheimers Dement. 2011; 7(3): 263-269. PubMed Abstract | Publisher Full Text | Free Full Text

6. American Diabetes Association (ADA): Standard of medical care in diabetes2020. Diabetes Care. 2020; 43: S1-S212.

Publisher Full Text

7. Linn BS, Linn MW, Gurel L: Cumulative illness rating scale. J Am Geriatr Soc. 1968; 16(5): 622-626.

PubMed Abstract | Publisher Full Text

8. Martocchia A, Frugoni $P$, Indiano I, et al.: Screening of frailty in elderly patients with disability by the means of Marigliano-Cacciafesta polypathology scale (MCPS) and Canadian Study of Health and Aging (CSHA) scales. Arch Gerontol Geriatr. 2013; 56(2): 339-342.

PubMed Abstract | Publisher Full Text
9. Guigoz Y, Vellas B, Garry PJ: Assessing the nutritional status of the elderly: The Mini Nutritional Assessment as part of the geriatric evaluation. Nutr Rev. 1996; 54(1 Pt 2): S59-S65.

PubMed Abstract | Publisher Full Text

10. Alexopoulos GS, Abrams RC, Young RC, et al.: Cornell Scale for Depression in Dementia. Biol Psychiatry. 1988; 23(3): 271-284.

PubMed Abstract | Publisher Full Text

11. Cummings JL, Mega M, Gray K, et al.: The Neuropsychiatric Inventory: comprehensive assessment of psychopathology in dementia. Neurology. 1994; 44(12): 2308-2314. PubMed Abstract | Publisher Full Text

12. Inouye $\mathrm{SK}$, van Dyck $\mathrm{CH}$, Alessi $\mathrm{CA}$, et al.: Clarifying confusion: the confusion assessment method. A new method for detection of delirium. Ann Intern Med. 1990; 113(12): 941-948.

PubMed Abstract | Publisher Full Text

13. Martocchia A: The Glycaemic Control and the Severity of the Delirium. DANS. 2020. http://www.doi.org/10.17026/dans-xq4-58fq

14. Dunning T, Sinclair A, Colagiuri S: New IDF Guideline for managing type 2 diabetes in older people. Diabetes Res Clin Pract. 2014; 103(3): 538-540. PubMed Abstract | Publisher Full Text

15. Glyconverter.tk: Glycated hemoglobin converter. Reference Source

16. Nathan DM, Kuenen J, Borg R, et al.: Translating the A1C assay into estimated average glucose values. [published correction appears in Diabetes Care 2009:32:207] Diabetes Care. 2009; 31(8): 1473-1478. PubMed Abstract | Publisher Full Text | Free Full Text

17. Kuenen JC, Borg R, Kuik DJ, et al:: Does glucose variability influence the relationship between mean plasma glucose and $\mathrm{HbA}_{1 \mathrm{c}}$ levels in type 1 and type 2 diabetic patients? Diabetes Care. 2011; 34(8): 1843-1847. PubMed Abstract | Publisher Full Text | Free Full Text 


\section{Open Peer Review}

\section{Current Peer Review Status:}

\section{Version 1}

Reviewer Report 13 July 2021

https://doi.org/10.5256/f1000research.28717.r89381

(C) 2021 Nagamine T. This is an open access peer review report distributed under the terms of the Creative Commons Attribution License, which permits unrestricted use, distribution, and reproduction in any medium, provided the original work is properly cited.

\section{Takahiko Nagamine}

1 Director of Sunlight Brain Research Center, Hofu, Japan

2 Department of Emergency Medicine, Matsumoto Surgical Hospital, Hofu, Japan

This paper analyzes HbA1c (blood glucose control status) and delirium in patients with Alzheimer's disease. It is interesting to note that both high and low blood glucose levels increase the risk of delirium. The paper is clinically significant because it shows that $\mathrm{HbA} 1 \mathrm{c}$ as a predictor of delirium may be valid.

If possible, two points should be considered: one is to conduct a study with separate analysis for the presence or absence of diabetes mellitus, and the other is to design the study to take into account the effects of antipsychotics and sleeping pills on blood glucose and delirium.

Alzheimer's disease is caused by a decrease in neurotransmission in the acetylcholine system. The central acetylcholine nervous system may be less responsive to glucose loading. Older patients with Alzheimer's disease may occasionally experience hypoglycemia. This is due not only to the decline in acetylcholine and other neurotransmitters in Alzheimer's disease itself but also to antipsychotic drugs used for delirium ${ }^{1}$.

The level of $\mathrm{HbA} 1 \mathrm{c}$ is also affected by the type of hypoglycemic drug. For example, concomitant use of insulin secretagogues (e.g., sulfonylureas) and dopamine blockers can cause hypoglycemia and delirium-like disturbances in consciousness ${ }^{2}$.

To avoid the effect of diabetic drugs, it is recommended to divide Alzheimer's disease into two groups, one with comorbid diabetes and the other without diabetes, and study the relationship between $\mathrm{HbA} 1 \mathrm{c}$ and delirium in each group. Delirium is influenced by Alzheimer's disease, but also by medications used to treat insomnia (e.g., benzodiazepine receptor agonists), so it is advisable to adjust for medications that have a risk of inducing delirium as a background factor ${ }^{3}$.

Even though there are confounding factors, the study of $\mathrm{HbA} 1 \mathrm{c}$ as a predictor of delirium is very unique and a good perspective from the point of view that Alzheimer's disease is called diabetes of the brain. 


\section{References}

1. Nagamine T: Severe hypoglycemia in an elderly patient withAlzheimer's disease and with sepsis: The role of neurotransmitters on glucose regulation. Geriatrics \& Gerontology International. 2021;

21 (1): 116-117 Publisher Full Text

2. Nagamine T: Severe Hypoglycemia Associated with Tiapride in an Elderly Patient with Diabetes and Psychosis.Innov Clin Neurosci. 14 (1-2): 12-13 PubMed Abstract

3. Nagamine T: Long-term preoperative use of zolpidem is associated with postoperative delirium in elderly patients undergoing hip surgery. Psychogeriatrics. 2021; 21 (4): 689-690 Publisher Full

Text

Is the work clearly and accurately presented and does it cite the current literature?

Yes

Is the study design appropriate and is the work technically sound?

Yes

Are sufficient details of methods and analysis provided to allow replication by others? Yes

If applicable, is the statistical analysis and its interpretation appropriate?

Partly

Are all the source data underlying the results available to ensure full reproducibility? Yes

Are the conclusions drawn adequately supported by the results?

Yes

Competing Interests: No competing interests were disclosed.

Reviewer Expertise: psychopharmacology, emergency medicine, diabetes

I confirm that I have read this submission and believe that I have an appropriate level of expertise to confirm that it is of an acceptable scientific standard.

Author Response 22 Jul 2021

Antonio Martocchia, Sapienza University of Rome, ROMA CAPITALE, Italy

Dear Prof Takahiko Nagamine,

We agree with the evidence about $\mathrm{HbA1c}$ as a predictor of delirium in Alzheimer's disease and with the interest about the effects of the presence/absence of diabetes mellitus or concurrent therapies (antipsychotics and sleeping pills, as well as insulin secretagogues, e.g. sulfonylureas, and dopamine blockers) on $\mathrm{HbA} 1 \mathrm{c}$ and delirium.

In our sample of AD patients with diabetes, one subject was treated with repaglinide (we added a sentence in the text in methods). 
The percentage of use of drugs (antipsychotics, sleeping pills, antidepressants, antidementia, antiparkinsonian agents, mood stabilizing medications) in AD patients with or without diabetes, were respectively: $37 \%, 19 \%, 19 \%, 6 \%, 19 \%, 6 \%$, and $32 \%, 18 \%, 23 \%, 9 \%$, 9\%, 9\% (differences not significant) (we added a sentence in the text, results and discussion). One AD patients with diabetes was treated with zolpidem. We added the suggested references in the bibliography's list. Yours sincerely, Antonio Martocchia, MD PhD

Competing Interests: No competing interests were disclosed.

Reviewer Report 17 May 2021

https://doi.org/10.5256/f1000research.28717.r85330

(C) 2021 Sigala S. This is an open access peer review report distributed under the terms of the Creative Commons Attribution License, which permits unrestricted use, distribution, and reproduction in any medium, provided the original work is properly cited.

\section{Sandra Sigala}

Section of Pharmacology, Department of Molecular and Translational Medicine, University of Brescia, Brescia, Italy

The Ms entitled "The effects of the glycaemic control on the severity of the delirium in the advanced phase of Alzheimer's disease" by Martocchia and coll is very interesting and gives support to the evidence that glycemic control in the frail elderly is important in slowing cognitive degeneration/Alzheimer's onset.

Authors highlighted as well the importance in these patients of a comprehensive clinical evaluation, which includes both biochemical and functional values.

The main limit of the study is the sample size, but this point has been taken up and discussed by the Authors themselves.

I have only minor points to underline:

1. The first sentence in the Introduction needs a reference

2. Characters in the Figure legend need to be unified - Figure 3 is hard to read

3. Throughout the Ms, please correct typos and the language style

Is the work clearly and accurately presented and does it cite the current literature? Yes

Is the study design appropriate and is the work technically sound? 
Yes

Are sufficient details of methods and analysis provided to allow replication by others? Yes

If applicable, is the statistical analysis and its interpretation appropriate?

Yes

Are all the source data underlying the results available to ensure full reproducibility?

No source data required

Are the conclusions drawn adequately supported by the results?

Yes

Competing Interests: No competing interests were disclosed.

Reviewer Expertise: Clinical pharmacology; translational oncology

I confirm that I have read this submission and believe that I have an appropriate level of expertise to confirm that it is of an acceptable scientific standard.

Author Response 22 Jul 2021

Antonio Martocchia, Sapienza University of Rome, ROMA CAPITALE, Italy

Dear Reviewer Prof Sandra Sigala,

We really appreciated your review, discussing the importance of a comprehensive clinical evaluation in frail elderly with Alzheimer's disease.

We agree that the limit of study is the sample size: we completed the sentence in the manuscript in the Discussion: "The variability of glycaemia seemed to be associated with greater BPSD in AD patients, although it was not possible to carry out a statistical analysis because of the few number of patients in the sample (a limit of the study)".

We added the reference (1) and modified the first sentence: "Behavioral and psychological symptoms of dementia (BPSD) and delirium are common in the advanced phases of Alzheimer's disease (AD) and worsen with disease severity, whereas symptoms of cognitive decline may be prevalent in the first phases of the disease (1)".

We unified the characters in the figure legends.

We modified the figure 3.

We corrected typos and the language style throughout the Ms.

Yours sincerely Antonio Martocchia, MD PhD

Competing Interests: No competing interests were disclosed. 
The benefits of publishing with F1000Research:

- Your article is published within days, with no editorial bias

- You can publish traditional articles, null/negative results, case reports, data notes and more

- The peer review process is transparent and collaborative

- Your article is indexed in PubMed after passing peer review

- Dedicated customer support at every stage

For pre-submission enquiries, contact research@f1000.com 